\title{
Translanguaging as Foundational Pedagogy: Disrupting Hegemonies for Academic Access in Multilingual Spaces
}

\section{Sindiso Zhou \\ Nhlanhla Landa}

\begin{abstract}
The grand objective of foundational pedagogy is underpinned by an endeavour to create access to higher education for marginalised learners. Without a deliberate plan of action to bridge the knowledge and skills gap, it would be challenging for learners to proceed to, and progress in, higher education institutions. In the multilingual South African space, language is essential in access to education given the legacies of colonialism and apartheid. However, language is currently a tool of exclusion in SA University classrooms. It is against this background that this paper disrupts the prevailing hegemony of English, using translanguaging: a subversive theory that acknowledges linguistic and cultural diversity. This paper shifts prevailing monolingual cultures, and explores practical ways of designing instruction that accommodates multilingual repertoires. We reflect on the rich linguistic canvas, initiate necessary conversations and ask relevant questions in an attempt to transform the educational experience for learners in marginalised contexts. This paper challenges attitudes of delegitimizing multilingual practices and branding them as corrupted and unacceptable. We acknowledge that sites of education are sites of legitimate struggle for decolonisation and transformation. Therefore, through translanguaging, learners' plural identities and humanity are embraced. Most importantly, foundation learners are free to use their complete linguistic repertoire to access knowledge without prejudice.
\end{abstract}

Keywords: translanguaging, disrupting hegemony, indigenous language, epistemic access 


\section{Introduction and Background}

As South Africa emerged from the pre-independence era, which was characterised by many inequalities and social injustices, several changes took place. These changes could not exclude changes in the linguistic environment, which had been characterised by a subtractive language policy that excluded the indigenous languages spoken by the majority of South Africans, and which had been at the centre of the struggle against apartheid by the black majority. The conspicuous domination of English and Afrikaans in pre-independent South Africa could not go unchecked by the post-Apartheid regime (Osborn 2007; Language Policy for Higher Education 2002; Council of Higher Education Policy Framework 2001; Language in Education Policy 1997). The enactment of these policies, which sought to realise the provisions of the South African Constitution, is evidence of efforts to correct the language imbalances of the apartheid era in South Africa. However, in the case of the education system, the legacies of the apartheid era still abound. This has caused the current debate on decoloniality and decolonisation of the education system. Again, the question of language, specifically the question of the language of instruction that should be used, which is very central to any debate on decoloniality, emerges.

This paper grapples with issues of how language pedagogy can be reconfigured to improve epistemological access for students at the foundational level. The expected outcome is to transform formal access into epistemic access. Epistemic access describes actual access to the knowledge that an institution distributes to learners. We argue that while the problem of epistemic access has multiple causes and manifestations (Morrow 2007; Paxton 2007), the language barrier is a huge and most central determinant (McKay 2014; Theron \& Nel 2005). We offer translanguaging as a possible solution to the challenge of language of instruction, and by extension the challenge of epistemic access for foundational pedagogies.

As a theory, translanguaging takes a lot from the concept of bilingual education and instruction. In bilingual instruction, learners and teachers are able to interact, negotiate meaning and transfer cognitive and linguistic skills in an environment conducive for free and active participation in more than one language (Cummins 2007a; Krashen \& Brown 2007; Benson 2005; Cummins 2000). These feed into effective teacher-learner-content interaction described in the Dialogic and Cognitive Pedagogy Model of Learning and Social 


\section{Sindiso Zhou \& Nhlanhla Landa}

Interaction (Zhou \& Landa 2018). Translanguaging may be viewed as a tool of meaning-making through use of languages within the reach of learners as they attempt to access discipline-specific knowledge. By description, translanguaging is more about communication than language proficiency. Translanguaging highlights the difference between a named standardized language, and the ability to use multiple languages for various tasks including academic tasks and purposes. The true measure of what a bilingual child can do comes out as they use all the languages within their mental lexicon, thus translanguaging. Unless we critically question and challenge the subtractive linguistic practices in our institutions, the potential of language minoritized students is wasted. Translanguaging emphasises dialogic learner-centered instruction that always puts the learner first.

Current university culture tends to promote monolingual pedagogies in which English dominates during instruction (with the exception of Afrikaans dominant universities and in(directly) uses monolingualism to exclude and marginalize learners. We approach our theorisation of translanguaging as a foundational pedagogy with the underlying belief that for translanguaging to be practised in the multilingual classroom; there should be systematic strategies on how to operationalize it. Translanguaging disrupts social conventions of subtractive educational contexts and dominant monolingual perspectives. Given that multilingual skills represent a prized competency in the employability skills-set in the global economy, learners from rural schools also need to access opportunities to be active in the global economy. The paper outlines strategies for creating translanguaging spaces in a multilingual environment through the development of three strands of a translanguaging pedagogy involving the teacher's stance, instructional and assessment design, and shifts in pedagogic practice.

In many post-colonial African nation states, languages of instruction have impeded epistemic access and pedagogical success as they have constructed alien learning environments for, especially, first year black students (Qunta 2008). Languages of instruction have also generally thwarted language development (Magwa 2015; Bamgbose 2000). However, literature indicates that the success of academic endeavours is irretrievably linked to medium of instruction (Magwa 2015; Tamtam et al. 2013; Lafon 2008; Lolwana 2005; Biseth 2005), and language of assessment. This has led to failed contact between learners in foundational programmes and knowledge. Therefore, 'an English-only or even an English-mainly policy' has significant disadvantages 
for any national processes (Alexander 2004). Learners in foundational education are at a disadvantage due to weaknesses in academic performance in general and under-preparedness for tertiary education due to poor secondary school learning conditions, ill-resourced rural secondary schools and inadequately trained rural and urban school teachers (Maforah \& Schulze 2012; Bloch 2009; Christie 2008). The continued poor performance of these students, which marks the difference between mere physical access to higher learning institutions and epistemic access, renders efforts of initiatives such as the free education movement fruitless. Du Ploy and Zilindile (2014), and Alexander (2008), discuss the differences between the forms of access to education. Further, Cross (2007) differentiates between access to campus and access to knowledge. Foundation students are caught up in this access paradox whereby they enjoy the privilege to access universities, yet in reality, the language in which higher education knowledge is packaged in renders the knowledge inaccessible.

Practice in the past has been to insist on monolingualism and separation of languages in the learning environment to promote and enhance foreign language acquisition and learning (Portoles \& Marti 2017) as well as second language acquisition. This reductionist approach most likely stemmed from the view that for effective acquisition and learning of a language, there is need for immersion in that language (Savage \& Hughes 2014; Schwartz 2009) and the input must be comprehensible (Krashen 2003), making the use of any other language in that space punishable in most school practices. At best, practice has also been bilingualism, which, following Heller (1999), at first was fashioned under 'parallel monolingual' models.

\section{Literature Review}

Revolutionising classroom practice has been widely investigated; however, the focus has largely been on outcomes after assessment. Little has been reported concerning actual classroom practice.

This article focuses on the processes that are undertaken in the language classroom - specifically, the foundation English for Specific Purposes class and the strategies involved in empowering learners and actual outcomes of that practice. 


\section{Extended Curriculum Programme in South Africa and Implications for Pedagogy}

The Extended Curriculum Programme (ECP), a child of the Draft National Plan for Education (RSA Department of Education 2001), was born out of the need 'to redress inequalities of the past and to ensure equitable access and success' of higher education (Julius 2017:5). Ensuring access without putting in place measures to ensure success was proving fruitless as enrolment improved but did not translate to increased graduates. The ECP was, therefore, implemented to ensure that first year students were able to build a strong academic foundation to allow them to transcend access to get to success in their studies. The programme was implemented in such a way that it is adjustable to suit the needs of each university (Council for Higher Education 2013). The South African ECP has similarities with programmes from other countries which seek to attain the same results in higher and tertiary education; these include Ireland and Scotland (Dhunpath \& Vithal 2014).

As Lange (2017) indicates, epistemological access was central to the introduction and implementation of the foundation programmes. These sought to provide 'extra scaffolding, especially in the areas of language and academic literacy' (Lange 2017: 41). The goal was to assist learners who had been inadequately trained in secondary education (Harris 2014). However, as Harris established, there are weak to no mechanisms put in place to ensure and measure the effectiveness of the ECP programme in some universities in South Africa.

\section{Epistemic Access}

South Africa is a typical example of what Omoniyi (1999) has described as multiethnicity-riddled sub-Saharan Africa. The South African University classroom is characterised by a multiplicity of indigenous African languages. In one class at the University of Fort Hare, for example, one can find in the same class students who speak isiXhosa, isiZulu, Sepedi, Yoruba, Shona, Southern isiNdebele and seSotho among a host of other African languages. In such an environment, the language question becomes key to epistemic access. Often, the language in education policy of the institution recognises one or two of these indigenous African languages. Therefore, there is more to the language of instruction question than allocating languages to institutions according to regional ethnic strata. 
Besides language issues, the South African education system is still characterised by inequalities and many unresolved challenges to epistemic access (Maforah \& Schulze 2012; Nel and Müller 2010; Hammett 2008). Learners from historically black schools continue to perform badly is some subject specifics and the situation does not promise to improve soon as long as schools in townships and rural areas do not receive special attention to uplift them to the level of schools that enjoy the urban advantage in towns and cities (Liccardo, Botsis \& Dominguez-Whitehead 2015). School location, therefore, has a bearing on the quality of epistemic access learners have. These differences in secondary education are carried to tertiary education as these different levels of access linger into the university, hence the ECP.

Cognitive and social advantages abound for epistemic access where multilingual learners use more than one language (Makalela 2015); thus, translanguaging in which learners harness all the linguistic resources within their reach for purposes of learning new concepts. Makalela insists that when boundaries between languages are transcended in a multilingual classroom, epistemic access is enhanced. Monolingualism in the classroom, or even parallel monolingualisms, puts a lot of pressure on multilingual learners (Garcia \& Wei 2014), and on monolingual learners whose language is not necessarily the one being used for instruction.

Makalela (2015) experimented with translanguaging in the teaching of Sepedi in a South African University to students who had not been previously exposed to the language, and to the teaching of English as a First Additional Language to primary school learners whose home language was Sepedi. The study concluded that epistemic access was greatly increased when translanguaging strategies were implemented. Further, translanguaging enhanced positive language-learning experiences for the learners, for whom alternation of languages in the classroom was received enthusiastically (Makalela 2015). The findings from Makalela's (2015:28) study that 'English reading proficiency skills can be enhanced through the use of the learner's language in the same lesson' are monumental and disruptive, showing the currency of translanguaging in enhancing epistemic access. Following Hurst, Madiba and Morreira's (2017) study on 'Surfacing and Valuing Students Linguistic Resources in an English-Dominant University'; the use of translanguaging in the social sciences significantly helps to allow deeper access to the concepts being learned. This is an indication that translanguaging is not limited to language teaching, but that using multiple languages is also 
useful in teaching concepts in different disciplines. We share Makalela's (2015:16) conviction that when learners have, at their disposal, more than one language to access content, understanding is better and deeper. However, in this paper we go beyond time-bound translanguaging whose only operationalisation is limited to the classroom.

\section{Translanguaging Theory: Framing Multilingual Interaction in the Foundation Classroom}

This section offers a brief description of translanguaging in the classroom from a scholarly viewpoint. A preview of translanguaging's original structure is essential in setting a necessary background on the practical ESP Translanguaging Framework that we experimented with at the University of Fort Hare with Foundation students in the Faculty of Social Sciences. Translanguaging refers to a process of 'communicating across and between different varieties of language/s' (Heugh 2015:2). This, Heugh adds, includes translation, interpretation and code-switching. It also covers what has been described as polylanguaging, codemeshing and metrolanguaging (Bloemmart 2010; Canagarajah 2011). In the education context, translanguaging achieves educational legitimacy in which education literally has meaning. It carries the promise of facilitating the transcending of the linguistic divide characterising the South African classroom context. It encourages 'multilingualism and multilingual pedagogies in the classroom' (Heugh 2015:2).

Translanguaging in class allows learners and teachers to pool linguistic and cognitive resources from all the languages available in a particular class's linguistic environment. In the first place, decolonisation of epistemic access does not imply a replacement of one system with another, but benefiting from a multiplicity of systems; systems of language teaching and learning; of education; of knowing; of doing things; and, indeed, of being. Translanguaging strategies bend to the needs of the learners at specific times, earning it the descriptor all-terrain (Garcia 2009); disrupting boundaries between languages in the effort to meet the communicative needs of the users (Garcia 2011; Makalela 2013).

As an approach to practice, translanguaging has the effect of multiplying the instructional voice as it allows learners to mediate and translate (teacher explanations and learning material) form one language into the other for the benefit of both the other learners and the teachers. It brings into play 
the concept of peer instruction, as opposed to the traditional practice of supplemental instruction where instruction is still limited to one (or two) supplemental instructor who, in many instances, also uses a dominant language like English or, if not, uses his/her home language and sticks to it or (code) switches between it and English. Either way, access is still not at its maximal. Differences between code-switching and translanguaging are discussed at length by Hornberger and Link (2012).

The challenge with multilingual set-ups, such as the University of Fort Hare, and indeed other South African universities and schools, is that improving epistemic access through language of instruction cannot be a simple issue of replacing English (or any other foreign or dominant language) with an indigenous language. Often, in the same mass-learning space characterising foundation classes at many universities in South Africa there are multiple languages, and, therefore, many learners whose indigenous (home) language is a language other than the dominant (and majority) indigenous language of the class. Further, in the same classes some learners' home language is English (or Afrikaans), making outright displacement and replacement of English (or Afrikaans where applicable) a disadvantage to some learners and some teachers.

The use of a language the learner is not comfortably competent in would impede their effective participation in whatever activity they are supposed to be part of. If the activity is academic, then the effect is major. As Garraway (2017) reports, confidence, both in the language of communication and in what one is saying is central to epistemological access. If learners lack confidence in their language competency, there is usually no voluntary participation in class activities that require them to speak or discuss. They also often find themselves at the mercy of other learners (Bozalek \& Boughey 2012), who often mock those who do not speak the language of instruction well. In classes other than language classes, the teacher's competence in the language of learning and teaching also becomes a critical issue (Pendleburry 2008; Ab Rahman et al. 2005).

Translanguaging in class, therefore, would allow learners to use whatever languages they are comfortable with and confident in. The next major question would be; what, then, should be the language of assessment in such a multilingual translanguaging class? Therefore, translanguaging answers the question that has been central in the debates about language in education policies; whose indigenous language should be promoted to the status of 
language of instruction? The answer that comes with translanguaging is; everyone's languages can be used to facilitate epistemic access.

\section{Motivation Driven by Agonising Experience}

The motivation to embark on a translanguaging experiment was necessitated by an agonising experience of teaching English for Specific Purposes to a Foundation class of 210 students in 2017 at the University of Fort Hare. After teaching ESP to the Foundation class for two weeks, it became evident that exclusive use of English during class was not working. Contact time was being wasted as there was no feedback. In this case, no feedback was the perfect feedback to indicate that not much learning was taking place. Students could not answer questions asked during class discussion due to their lack of confidence in speaking English. It became apparent that if any learning was going to take place, students had to participate in their own learning. They had to talk to each other, talk to the lecturer and talk to themselves with confidence. Dialogue is central to learning (Zhou \& Landa 2018). However, if it has been stated that this is an English class and the only way to succeed in English is to immerse oneself in all things English to the exclusion of any other language, then students who are not proficient in English automatically shut down for fear of being ridiculed. Evidently, an alternative way of thinking about learning was required. As a matter of survival and continuity, an alternative, practical, functional methodology had to be employed. To forge ahead, we had to disturb the hegemonic discourse that one can only learn English in English, and that English is the superstrate and dominant language of academic spaces.

With the challenge of delivering content successfully being our major preoccupation, the reality of multilingual classrooms was apparent. Like any space where individuals from various ethnicities, religions, genders and races converge, the classroom is a political space. As a political space, there is power at play. The very nature then, of a classroom as a space of serious contestation presents it as a space where significant change can be achieved. It is the potential of the classroom to be used as a space for positive change that prompted this notion of conceptualising subversion as emanating from the language of the learners during learning. If language has previously been used as a tool to separate, exclude and oppress, it can also be used for positive effect in the classroom. Given that knowledge has been packaged in Anglonormative terms, it should be expected that foundation students coming from a 
predominantly African background with home languages other than English should face challenges.

\section{The Dual Challenge of Access}

The dual task faced by foundation students is that of accessing English as a language of communication before they can understand the content that it is delivering. Language acquisition and learning are a package deal. Language is acquired and learnt alongside its culture. There are complex processes involved in language acquisition and learning, and as stated earlier in this paper, there are structural weaknesses in primary and secondary education hence learners come to university ill prepared. Once a language learner misses a stage and errors fossilize, it becomes difficult to revert to childhood level proficiency. Even after independence from the shackles of colonialism, English as a language continues to transport innuendoes of oppression and transmit hegemonies in its wake, especially if it is made to occupy epistemic spaces that the majority cannot access even though they are physically on a campus. This paper, therefore, uses the same tool of language to break the barrier that is blocking access to knowledge for foundation students.

\section{Experimental Translanguaging: The Case of Foundation English for Specific Purposes (ESP)}

Given the urgency of ensuring access to knowledge and skills of learners from marginalised backgrounds, it has become important to challenge canonical perspectives and concepts of higher education; to contest colonial definitions of knowledge and to disrupt entrenched practices of scripted curricula, hence our experiment with translanguaging in the Foundation English for Specific Purposes class. While searching for opportunities and practical ways of bringing translanguaging to life in an academic setting three strands of a translanguaging pedagogy involving the instructor's stance, instructional design, and shifts in pedagogic practice were explored. Stance focused on the instructor's beliefs with regards to language diversity. Instructional design focused on the design of the material being taught. Its flexibility and possibility for innovative delivery was a major factor in this instance. Lastly, shifts on delivery style where the readiness of the instructor to shift teaching styles in 


\section{Sindiso Zhou \& Nhlanhla Landa}

order to accommodate the translanguaging moments during a learning session is tested. These three strands underpinned activities undertaken during the experimental sessions.

Before embarking on the Translanguaging Experiment (TEX), students were briefed on language development. The brief was meant to explain how translanguaging works without misleading students into thinking that they were off the hook and they could write classwork in isiXhosa or seSotho. Content understanding is linked to learning ways of using the dominant language. However, given that any acquisition or learning of a new language depends on what is already known to the speaker, then making use of available resources makes productive sense and ensures both language and content development. On the contrary, the exclusive use of English in the classroom accompanied by an outright negation of indigenous languages has damaging consequences for foundation students who are vulnerable where English proficiency is concerned.

One of the skills that students have to acquire in ESP is that of writing essays in an academic setting. After exposition, students were assigned a group task on planning for an essay on Gender inequality in the workplace in South Africa. In groups of four, students drafted a comprehensive stage by stage plan (Introduction, thesis statement, proposition and so on following the conventions of academic writing). As opposed to pre-experimental activities in which it was attempted that English was the language of class business- there was vibrant and productive discussion that demonstrated surprisingly robust arguments from the foundation students. Innovation, versatility, linguistic multitasking, interpersonal relationships, connections and comradeship were developed while learning. Students owned their voices and expressed themselves as they participated in their own learning.

We broadened the concept of translanguaging by conceptualising a pedagogic paradigm that we labelled as the Learner Translanguaging Tools (LTT). Since the focus was on giving the learner voice, the learner is the central participant in the paradigm. The basis of the LTT paradigm is that participation of foundation students evolves as a result of the interaction of the following variables:

\section{a) Learner variables}

The background knowledge of students, their attitudes to learning, linguistic knowledge, enthusiasm and beliefs influence their 
participation in learning tasks. On the Gender Inequality task, the mere fact that some of the students identified with the topic somehow, as they were victims directly or indirectly, was enough to stimulate their interest in the subject.

\section{b) Learning material variables}

The understanding of the demands of task assigned, complexity of task assigned, cognitive demand, additional resources such as research articles, freedom to use the internet and social media to source information all facilitate readiness, confidence and determination to use all available linguistic resources to get the best possible outcome.

\section{c) Learning context variables}

The physical and social settings are both important in translanguaging. In the ESP TEX, the students were made to feel safe in the auditorium by allowing them to choose their group members before class. They chose group members based on similarity of home language, dialect and so on. This means that on the day of the task, they would be sitting in a comfortable, safe space where they could express themselves without fear of humiliation.

Consideration of all the variables of the LTT coupled with the stance, learning material and shifts' strands provided learner-friendly learning spaces in which students accessed knowledge on their own terms at their own pace. Indigenous words were used, translated to English and vice versa. Positive learning outcomes were recorded as tasks were completed and understanding was confirmed through positive feedback. While the shifts aspect in the original theory could pause challenges of disrupting linear class time, the Learning Context Variable in the LTT paradigm offers an opportunity to plan translanguaging learning sessions and to create translanguagable contexts. Not every learning session, topic and field will yield to translanguaging. However, stance, creativity and innovation are key in seeking translanguaging spaces and creating content that suits snugly the context of the learner. The irony of translanguaging is that there may be resistance to using multiple linguistic repertoires to clarify content in class but when students achieve pass marks, methodology used is not an issue. The activities outlined above are in line with Madiba's (2014) strategy of bringing the academic lexicon into indigenous 
languages. Consequently, using multilingual glossaries in learning spaces not only develops indigenous languages, but it also facilitates learning.

\section{Challenges in Operationalizing Translanguaging}

In order to address the inevitable disconnect that occurs between home language and language of instruction, we designed classroom activities that utilise both languages as a way of operationalising translanguaging in the ESP classroom.

When structured systematically and contextually, translanguaging can facilitate epistemological access by overturning the dominant paradigm of English as the standard. In addition, solid identities are created when home languages are elevated as tools of opening knowledge spaces (Childs 2016; Heugh 2015; Garcia \& Wei 2015). It is important to note that both covert and overt curriculum practices can disempower or empower students. Therefore, the group discussions on writing practice sought the active involvement of learners in the learning process. The learners had the responsibility of not only understanding the concepts discussed but also making other group members do so. This responsibility allowed learners to feel more confident about their contribution.

Further, the discussions allowed interaction with learning material and with fellow learners at a group level. During the feedback sessions in a wholeclass activity, learners were more confident in their participation as they felt they were representing their group. Translanguaging strengthened learners' confidence as they switched from one language to another and from one learning approach to another and their contributions were translated and interpreted to the dominant medium of instruction by other learners and by the instructor. This multiplied the voice of instruction in the class as learners also had the responsibility of explaining content in the class. Those learners who were competent in English but not necessarily knowledgeable in the content being discussed in class also benefited immensely from the contributions they were often called upon to translate into English.

The discussions also encouraged brainstorming and note-making in both the students' L1s and English, which was anticipated as a means to improve access to content and learner interest in the content. The strength of brainstorming lies in its provision of an unrestricted exploration of ideas for creativity and innovation by individuals and groups. We also encouraged 
student-made multilingual vocabulary note books. These, when implemented alongside other academic processes like research and extensive reading, have a positive effect on learning (Centenario 2013).

Despite its emancipatory nature and positively disruptive to hegemonies conceptual frame, translanguaging has inherent tensions when operationalised. Specific strategies should be taken into cognizance and adhered to in instructional design and delivery, especially where large numbers are concerned. Class management, fragmentation of topics and proximity to student task execution are some of the demands that we had to grapple with. As observed in the practical sessions, appreciation of the home language can positively lead to understanding of the English language, a fundamental issue in multilingualism as discussed by Cummins (1979).

\section{Conclusion}

This paper set out to explore translanguaging theory as a foundational pedagogy that has the potential of disrupting language and knowledge hegemonies for epistemic access in multilingual spaces such as are found in South Africa. As indicated by the ESP Translanguaging Experiment, translanguaging presented students with a novel experience of savouring the learning experience: freedom to engage with peers, content and instructor. The rigid classroom atmosphere, known in monolingual scripted curricula, resulting in tense students, was completely erased by the comfortable, humane and communal atmosphere of dialogic, cooperative and communicative language learning aided by translanguaging. Foundation students enjoyed the autonomy and flexibility to use their languages in productive ways while accessing new knowledge. Critical thinking and versatility are some of the key skills that were nurtured through translanguaging in the ESP TEX.

As observed in the experimental activities, acknowledging the students' full linguistic repertoire as a resource allows them to externally leverage their language repertoire in its entirety. No features are suppressed out of fear of ridicule by peers. The two or three languages known are consciously activated and allowed to systematically interface and work together to make sense of new knowledges. Multilingual students think and perform better when they feel that their home languages are not being judged as inferior in the classroom. In practice, translanguaging gives voice to students. For foundation students who tend to be patronised by the mainstream 
students implying that they are slow or not competent enough, translanguaging is the crutch they need to lean on as they navigate the university terrain attempting to access knowledge in various disciplines for their own academic success. We acknowledge that sites of education are sites of controversy as well as legitimate struggle for decolonisation and transformation. However, it is through subversion that the voices of the marginalised can be heard. Therefore, through translanguaging, learners' plural identities and humanity are embraced and positive learning outcomes are achieved. Most importantly, foundation learners are free to use their complete linguistic repertoire to access knowledge without prejudice.

\section{References}

Ab Rahman, H., A. Nordin, M. Isa, F. Puteh, F. Muhammad, N. Abd Majid, A.A. Khalid, S.F. Bahari, H.S Tumin \& Z. Zakariya 2005. Teachers' Competency in the Teaching of Mathematics in English in Malaysian Secondary Schools. The Mathematics Education into the $21^{\text {st }}$ Century Project: Reform, Revolution and Paradigm Shifts in Mathematics Education. Malaysia: Universiti Teknologi Malaysia.

Alexander, N. 2004. The Politics of Language Planning in Post-apartheid South Africa. Language Problems \& Language Planning 28, 2: 113 - 130. Amsterdam: John Benjamins Publishing Company. Available at: https://www0.sun.ac.za/taalsentrum/assets/files/Alexander\%20Lang\%20 Planning\%20in\%20Post-Apartheid\%20SA.pdf. (Accessed on 15 October 2018.) https://doi.org/10.1075/lplp.28.2.02ale

Alexander, R. 2008. Education for All, the Quality Imperative and the Problem of Pedagogy. CREATE Research Monograph 20:1 - 60. Available at: http://www.create-rpc.org/pdf documents/PTA20.pdf. (Accessed on 20 February 2019.)

Ball, A. 2005. US and South African Teachers' Developing Perspectives on

Language and Literacy: Changing Domestic and International Roles of

Linguistic Gate-keepers. In Makoni, S., G. Smitherman, A. Ball and A.K

Spears (eds.): Black Linguistics. London: Routledge Publications.

Bamgbose, A. 2000. Language and Exclusion: The Consequences of Language Policies in Africa. London: Transaction Publishers.

Benson, C. 2005. Girls, Education Equity and Mother Tongue-based Teaching. UNESCO: Bangkok. 
Biseth, N. 2005. Language in Education Influenced by Global Trends - South African Experiences. Paper presented at the TETREED Conference at Beistolen 5 - 7 December 2005.

Bloch, G. 2009. The Toxic Mix: What's Wrong with South Africa's Schools and How to Fix it. Cape Town: Tafelberg.

Blommaert, J. 2010. The Sociolinguistics of Globalisation. Cambridge: Cambridge University Press.

Bozalek, V. \& C. Boughey 2012. (Mis)framing Higher Education in South Africa. Social Policy and Administration 46, 6: 688 - 703. Available at: https://doi.org/10.1111/j.1467-9515.2012.00863.x. (Accessed on 12 November 2018.)

Canagarajah, S. 2011. Codemeshing in Academic Writing: Identifying Teachable Strategies of Translanguaging. Modern Language Journal 95:401 - 417. https://doi.org/10.1111/j.1540-4781.2011.01207.x

Centenario, L.L. 2013. Vocabulary Notebooks: A Tool to Enhance Memory or a Memories Notebook? Masters Thesis, Universidad Pública de Navarra.

Childs, M. 2016. Reflecting on Translanguaging in Multilingual Classrooms: Harnessing the Power of Poetry and Photography. Educational Research for Social Change 5, 1: 22 - 40. Available at:

http://ersc.nmmu.ac.za/articles/ERSC Vol 5 No 1 Childs pp 22 to 4 0_April_2016.pdf. (Accessed 20 January 2018.) https://doi.org/10.17159/2221-4070/2016/v5i1a2

Christie, P. 2008. Opening the Doors of Learning. Changing Schools in South Africa. Johannesburg: Heinemann.

Council for Higher Education 2001. Language Policy Framework for South African Higher Education. Pretoria: Government Printers.

Council for Higher Education 2013. A Proposal for Undergraduate Curriculum Reform in South Africa. The Case for a Flexible Curriculum Structure. Pretoria: Government Printers.

Cross, M. 2007. Access to Campus or Access to Knowledge? The Challenge of Higher Education Transformation in South Africa. Paper presented at the IIEP, Paris 24 May 2007.

Cummins, J. 2007. Biliteracy, Empowerment, and Transformative Pedagogy. [J. Cummins ESL and Second Language Learning Web]. Available at: http://www.iteachilearn.com/cummins/biliteratempowerment.html. (Accessed on 10 December 2008.) https://doi.org/10.21832/9781853596773 
Cummins, J. 2000. Language, Power and Pedagogy: Bilingual Children in the Crossfire. Toronto: Multilingual Matters Ltd.

Dhunpath, R. \& R. Vithal 2014. Alternative Access to Higher Education. Underprepared Students or Underprepared Institutions? Cape Town: Pearson Education South Africa (PTY) Ltd.

du Plooy, L. \& M. Zilindile 2014. Problematising the Concept of Epistemological Access with Regard to Foundation Phase Education towards Quality Schooling. South African Journal of Childhood Education 4, 1: 187 - 201. https://doi.org/10.4102/sajce.v4i1.51

Garcia, O. 2009. Bilingual Education in the 21 ${ }^{\text {st }}$ Century: A Global Perspective. Malden, MA: Wiley/Blackwell.

Garcia, O. 2011. From Language Garden to Sustainable Languaging: Bilingual Education in a Global World. Perspectives 34, 1: 5 - 9.

Garcia, O. \& L Wei 2014. Translanguaging: Language, Bilingualism and Education. London: Palgrave Pivot.

https://doi.org/10.1057/9781137385765 4

Garraway, J. W. 2017. Participatory Parity and Epistemological Access in the Extended Curriculum Programmes. Education as Change 21 2: 109 - 125. Available at: http://www.scielo.org.za/pdf/eac/v21n2/07.pdf (Accessed 17 October 2018.) https://doi.org/10.17159/1947-9417/2017/2008

Hammett, D. 2008. Disrespecting Teacher: The Decline in Social Standing of Teachers in Cape Town, South Africa. International Journal of Educational Development 28, 3: 340 - 347.

https://doi.org/10.1016/j.ijedudev.2007.05.007

Harris, F. 2014. An Assessment of the Extended Curriculum Programme at a University of Technology Using Quality Management Principles. Masters Thesis. Faculty of Engineering, Cape Peninsula University of Technology.

Heller, M. 1999. Linguistic Minorities and Modernity: A Sociolinguistic Ethnography. London: Longman.

Heugh, K. 2015. Epistemologies in Multilingual Education: Translanguaging and Genre - Companions in Conversation with Policy and Practice. Language and Education 29, 3: 280 - 285. Available at:

https://doi.org/10.1080/09500782.2014.994529 (Accessed 12 August 2018.)

Hornberger, N. \& H. Link. 2012. Translanguaging and Transnational Literacies in Multilingual Classrooms: A Biliteracy Lens. International 
Journal of Bilingual Education and Bilingualism 15: 261 - 278.

https://doi.org/10.1080/13670050.2012.658016

Hurst E., M. Madiba \& S. Morreira 2017. Surfacing and Valuing Students'

Linguistic Resources in an English-Dominant University. In Palfreyman,

D.M. \& C. van der Walt (eds.): Academic Biliteracies: Multilingual

Repertoires in Higher Education. Bristol: Multilingual Matters.

https://doi.org/10.21832/9781783097425-007

Julius, C. 2017. Nursing Students' Perceptions of an Extended Undergraduate

Curriculum Programme within a Higher Education Institution in the

Western Cape Province. Masters Thesis. Faculty of Medicine and Health

Sciences, Stellenbosch University, South Africa.

Krashen, S. \& C.L. Brown 2007. What is Academic Language Proficiency?

Language \& Communication Review 6, 1: 1 - 4. Available at:

https://files.eric.ed.gov/fulltext/ED505950.pdf (Accessed 16 October 2018.)

Krashen, S. 2003. Explorations in Language Acquisition and Use: The Taipei Lectures. Portsmouth, NH: Heinemann.

Lafon, M. 2008. African Languages for All, a Powerful Strategy for

Spearheading Transformation and Improvement of the South African

Education System. IFAS Working Paper.

Lange, L. 2017. 20 Years of Higher Education Curriculum Policy in South Africa. Journal of Education 68: 31 - 58. Available at:

http://www.scielo.org.za/pdf/jed/n68/04.pdf. (Accessed 20 January 2019.)

Language in Education Policy 1997. Available at:

https://www.education.gov.za/Portals/0/

Documents/Policies/GET/LanguageEducationPolicy1997.pdf?ver=200708-22-083918-000. (Accessed on 27 August 2017.)

Language Policy for Higher Education 2002.

http://www.dhet.gov.za/Management-Support/Language-Policy-for-

Higher-Education.pdf (Accessed 20 August 2017.)

Liccardo, S., H. Botsis \& Y. Dominguez-Whitehead. 2015. Background

Knowledge and Epistemological Access: Challenges Facing Black

Women in a Set Scholarship Programme. South African Journal of Higher

Education 29, 11: 373 - 389. Available at:

https://pdfs.semanticscholar.org/5879/6ac64670b794d48e80e64fbdb8c2

bdd79deb.pdf. (Accessed on 20 January 2019.) 
Lolwana, P. 2005. Where to with Matric? Matric: What is to Be Done? Umalusi Seminar Series 64-74. Available at:

https://www.umalusi.org.za/docs/assurance/2005/matric.pdf.

(Accessed March 2019.)

Madiba, M. 2014. Promoting Concept Literacy through Multilingual Glossaries: A Translanguaging Approach. Linguistics and Education 24, 4: 385 - 395. Available at: http://dx.doi.org/10.1016/j.linged.2013.09.002. (Accessed 25 January 2019.)

Maforah, T.P. \& S. Schulze 2012. The Job Satisfaction of Principals of Previously Disadvantaged Schools: New Light on an Old Issue. South African Journal of Education 32, 3: 227 - 239. Available at:

http://www.scielo.org.za/scielo.php?script=sci_abstract\&pid=S0256-

01002012000300001\&lng=en\&nrm=iso. (Accessed on 3 February 2019.) Magwa, W. 2015. Attitudes towards the Use of Indigenous African Languages as Languages of Instruction in Education: A Case of Zimbabwe. Journal of Education Policy and Entrepreneurial Research (JEPER) 2, 1:1 - 16. Available at:

https://pdfs.semanticscholar.org/f155/b29f5f86c104bc2ce6c5b47b36deb 88440f6.pdf. (Accessed on 23 September 2018.)

Makalela, L. 2013. Translanguaging in kasi-taal: Rethinking Old Language Boundaries for New Language Planning. Stellenbosch Papers in Linguistics Plus 42: 111-125. Available at:

http://citeseerx.ist.psu.edu/viewdoc/download?doi=10.1.1.904.3971\&rep $=$ rep1\&type $=$ pdf. (Accessed 12 January 2019.)

https://doi.org/10.5842/42-0-164

Makalela, L. 2015. Translanguaging as a Vehicle for Epistemic Access: Cases for Reading Comprehension and Multilingual Interactions. Per Linguam: A Journal for Language Learning 31, 1: 15 - 29. Available at:

http://perlinguam.journals.ac.za/pub/article/view/628. (Accessed on 12 January 2019.)

https://doi.org/10.5785/31-1-628

McKay, B. D. 2014. Learning Support to Grade 4 Learners who Experience Barriers to English as Language of Learning and Teaching. Thesis: University of South Africa, Pretoria.

Morrow, W. 2007. Bounds of Democracy: Learning to Teach in South Africa. Cape Town: HSRC Press.

Nel, N. \& H. Müller 2010. The Impact of Teachers' Limited English Proficien- 
cy on English Second Language Learners in South African Schools. South African Journal of Education 30, 4: 635 - 650. Available at: http://www.scielo.org.za/scielo.php?script=sci arttext\&pid=S0256-

01002010000400009. (Accessed on 2 January 2019.)

https://doi.org/10.15700/saje.v30n4a393

Omoniyi, T. 1999. Bilingualism, Biliteracy, Classrooms and Identity Politics

in Sub-Saharan Africa. Opinion Papers (120). U.S. Department of Education, Educational Resources Information Center (ERIC).

Paxton, M. 2007. Students' Interim Literacies as a Dynamic Resource for

Teaching and Transformation. South African Journal of Applied Language Studies (SAJALS) 5, 1: 1 - 12. Available at:

https://www.tandfonline.com/doi/pdf/10.2989/16073610709486445?nee dAccess $=$ true.. (Accessed 12 January 2019.)

https://doi.org/10.2989/16073610709486445

Pendlebury, S. 2009. Meaningful Access to Basic Education: The South African Child Gauge 2008/2009 Report. South Africa: Children's Institute.

Portolés, L. \& O. Martí 2017. Translanguaging as a Teaching Resource in Early Language Learning of English as an Additional Language (EAL). Bellaterra Journal of Teaching \& Learning Language \& Literature 10, 1: 61-77. Available at:

http://gruplaela.uji.es/sites/default/files/portoles\%26marti_2017.pdf.

(Accessed on 12 June 2019.) https://doi.org/10.5565/rev/jtl3.698

RSA Department of Education 2001. Draft National Plan for Higher Education in South Africa. Ministry of Education (February). Available at: http://www.dhet.gov.za/HEDPolicies/National\%2 (Accessed on 03 March 2014.)

Savage, B. L. \& H. Z. Hughes 2014. How does Short-term Foreign Language Immersion Stimulate Language Learning? Frontiers: The Interdisciplinary Journal of Study Abroad 24: 103 - 120. Available at: https://files.eric.ed.gov/fulltext/EJ1062133.pdf (Accessed on 29 January 2019.)

Schwartz, N.A. 2009. Air Force Culture, Region, and Language Flight Plan. Washington, DC: United States Air Force.

Tamtam, A., F. Gallagher, S. Naher \& A. Olabi 2013. The Impact of Language of Instruction on Quality of Science and Engineering Education in Libya: Qualitative Study of Faculty Members. European 
Scientific Journal 9, 31: 19 - 36. Available at:

http://eujournal.org/index.php/esj/article/view/2045. (Accessed on 20 August 2017.)

Theron, L. \& M. Nel 2005. The Needs and Perceptions of South African Grade 4 Educators, Teaching English Second-language (ESL) Learners. Africa Education Review 2, 2: 221 - 241. https://doi.org/10.1080/18146620508566302

Zhou, S. \& N. Landa 2018. Dialogic Communication: Reviving Mathematics and Science Pedagogy for the $21^{\text {st }}$ Century. The Social Sciences: Medwell Journal 13, 6: 1133 - 1141. Available at: http://docsdrive.com/pdfs/medwelljournals/sscience/2018/11331141.pdf. (Accessed 13 January 2019.)

Sindiso Zhou English and Comparative Studies University of Fort Hare szhou@ufh.ac.za

Nhlanhla Landa English Department University of Fort Hare nlanda@ufh.ac.za 